\title{
Study of the Structure and Thermal Properties of Intermetallics from Fe-Al System
}

\author{
A. Śmiglewicz* M. Jabłońska, K. Rodak and A. Tomaszewska \\ Silesian University of Technology, Faculty of Materials Science and Metallurgy, \\ Z. Krasińskiego 8, 40-019 Katowice, Poland
}

\begin{abstract}
Selected alloys from the $\mathrm{Fe}-\mathrm{Al}$ system are included into a group of materials on a matrix of intermetallic phases, and characteristic properties result from it and they constitute a resultant between properties of superalloys and ceramic materials. These materials are characterized, inter alia, by capacity for operating at elevated temperatures, as well as good strength related properties and resistance to oxidation and corrosion at an increased temperature. In addition, a low cost of alloy components and low density caused by aluminium content are their advantages. The basic reasons limiting application of alloys from $\mathrm{Fe}-\mathrm{Al}$ system as construction materials are current: their low plasticity at room temperature, propensity for brittle cracking, low resistance at elevated temperature, and insufficient creep resistance. This unfavorable characteristics may be improved by adding to alloys such elements as molybdenum, zirconium, carbon, and boron, reducing the size of grains, increasing their purity, stabilizing the solid solution, and causing changes in phase transition temperatures. These alloys may be successfully manufactured by classic melting accompanied with refinement remelting, and ingot casting. In spite of additions and microadditions, grain refining of the initial structure of ingots manufactured in that way is rarely achieved, mainly because of low castability and high casting contraction. In this work we presented the results of structure analysis and investigations of the dilatometric study alloys on the base $\mathrm{Fe}-\mathrm{Al}$ system. The alloys were obtained by classic casting technique. The studies were carried out on samples after casting and annealing. The phase transformation and thermal expansion investigations of the alloys from $\mathrm{Fe}-\mathrm{Al}$ system with concentration of $\mathrm{Fe}-58 \mathrm{Al}$ were presented. The linear thermal expansion $\alpha$ was calculated by standard method. The $\alpha$ coefficient was noticed as a temperature function.
\end{abstract}

DOI: 10.12693/APhysPolA.130.1004

PACS/topics: 81.70.Pg, 65.40.De, 65.60.+a, 07.20.-n

\section{Introduction}

Development of these alloys depends on a thorough understanding of their physical and thermal properties, and deformation mechanisms in relation to the defect structure in these materials. Experimental as well as theoretical studies [1-5] suggest that knowledge about degree and type of order and defects in iron aluminides is very important. The knowledge on the phase transformations in these alloys including the information about order-disorder transition is very valid from the point of view of obtained mechanical and physical properties of alloys of the $\mathrm{Fe}-\mathrm{Al}$ system [6]. The results are the valid supplement for development knowledge of these alloys. This paper describes results of thermal analysis in $\mathrm{Fe}-\mathrm{Al}$ alloys in comparison with dilatometric study. The temperature of the tests was selected based on analysis of phase equilibrium system and based (Fig. 1) on available literature [7]. In Fig. 1, a fragment of the $\mathrm{Fe}-\mathrm{Al}$ phase equilibrium system according to Kubaschewski [7] is shown. The line denotes chemical composition of the analyzed $\mathrm{Fe}-58 \mathrm{Al}$ alloy.

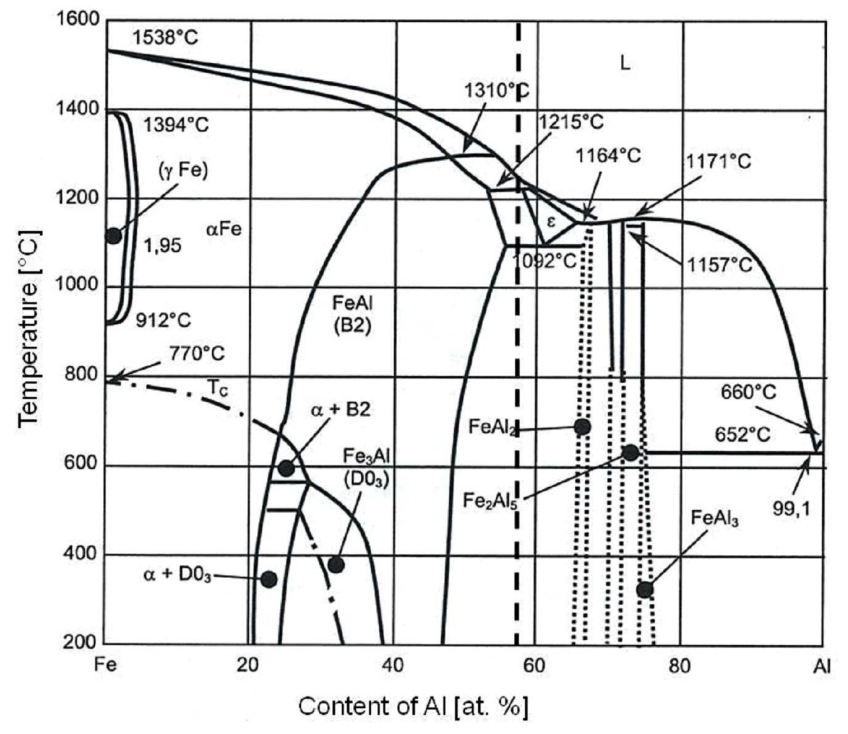

Fig. 1. Al-Fe phase equilibrium system according to Kubaschewski [7]. 


\section{Experimental}

The material for the research consisted of samples taken from binary alloys of the $\mathrm{Fe}-\mathrm{Al}$ system, containing 58 at. $\mathrm{Al}$, prepared using vacuum indication melting (VIM) technique with triple refining remelt, and gravitational casting. Chemical composition of the alloys is shown in Table I.

TABLE I

Chemical composition of investigated $58 \mathrm{Al}$ [at.\%]

\begin{tabular}{c|c|c|c|c}
\hline \hline $\mathrm{Al}$ & $\mathrm{Fe}$ & $\mathrm{B}$ & $\mathrm{Zr}$ & $\mathrm{C}$ \\
\hline 58 & 41.84 & 0.01 & 0.05 & 0.10
\end{tabular}

The carbon and boron addition has been used in order to increase resistance of grain boundaries. In order to decrease grain sizes after the crystallization process, a modified form of zirconium has been used [8].

Then, the studied material was subjected to homogenising treatment at $1000^{\circ} \mathrm{C}$ for hold time of $24 \mathrm{~h}$, and furnace cooling. Dilatometric research was carried out using a SETSYS thermal analyser from SETARAM. The measurement of temperature was carried out using a thermoelement of $\mathrm{Pt}-\mathrm{Rh}$ type. The process of heating was conducted in an argon atmosphere with a heating rate of $5{ }^{\circ} \mathrm{C} / \mathrm{min}$. The linear thermal expansion $\alpha$ was calculated by standard method. The $\alpha$ coefficient as a temperature function is noticed.

X-ray diffraction investigations were carried out using a Philips diffractometer. Copper lamp, $\mathrm{Cu} K_{\alpha}$ radiation with wavelength $\lambda=1.54178$ Áwas applied. A graphite monochromator at diffracted beam was used during the research. X-ray phase analysis was carried out based on $\mathrm{X}$-ray diffraction lines of crystalline phases.

\section{Results and discussion}

For the investigated alloy, linear thermal expansion coefficient $\alpha$ has been determined, assuming the lack of phase transitions. Considering the occurrence of transformations during heating, it would be methodologically justified to determine the real $\alpha$. However, it is not routinely used for practical purposes, and that is why the average $\alpha$ in the range of linear increase in sample dimension in the investigated temperature range has been calculated, according to Eq. (1) [9]

$$
\alpha_{T 2-T 1}=\frac{l_{2}-l_{1}}{(\Delta T) l_{0}} .
$$

The investigated material containing 58 at.\% $\mathrm{Al}$ is characterized by a lower (while compared to the alloys with lower aluminum contents [6]) average linear thermal expansion coefficient, equal to $15.90 \times 10^{-6} /{ }^{\circ} \mathrm{C}$. In $200^{\circ} \mathrm{C} \div 700^{\circ} \mathrm{C}$ heating temperature range, the average value of linear thermal expansion coefficient is ca. $13.827 \times 10^{-6} /{ }^{\circ} \mathrm{C}$. After exceeding this temperature range, the value of $\alpha$ increases to ca. $23.341 \times 10^{-6} /{ }^{\circ} \mathrm{C}$. From $700{ }^{\circ} \mathrm{C}$, thermal expansion coefficient of the investigated material increases with the increase in heating temperature.

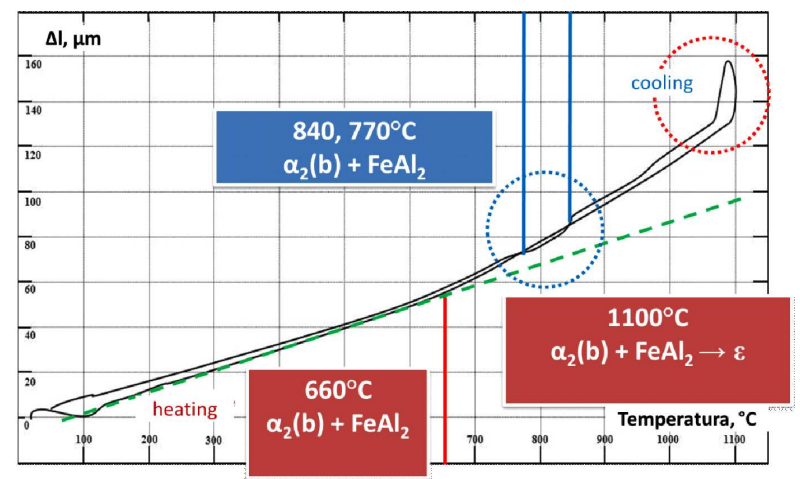

Fig. 2. The dilatometric curve for the alloy 58Al.

The dilatometric curve for the alloy $58 \mathrm{Al}$ is shown in Fig. 2. In the state after casting, the coefficient of linear thermal expansion $\alpha$ of the $58 \mathrm{Al}$ alloy changes linearly up to temperature of $c a .660^{\circ} \mathrm{C}$. Above $700^{\circ} \mathrm{C}$, the $\alpha$ coefficient increases exponentially up to temperature of the heating end $\left(1100^{\circ} \mathrm{C}\right)$, in which the thermal expansion increases rapidly, probably due to the formation of a phase $\varepsilon$. At a temperature of about 840,770 , and $680^{\circ} \mathrm{C}$ on the dilatometric curve appear minor faults - sudden changes in linear thermal expansion coefficient $\alpha$. These changes are not the result of phase transitions, but may be caused by reassemble atoms in the $\alpha_{2}(b)+\mathrm{FeAl}_{2}$ eutectic.

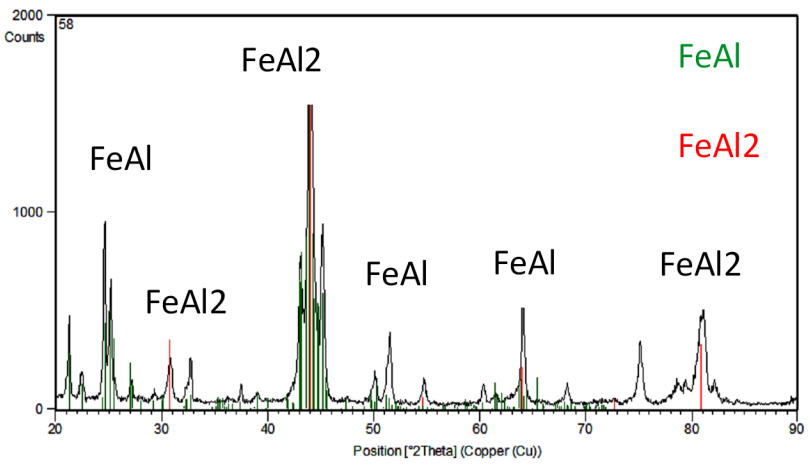

Fig. 3. X-ray diffractogram of $58 \mathrm{Al}$ alloy $\mathrm{FeAl}$ matrix $+\mathrm{FeAl}_{2}$ phase.

Classic carried out X-ray phase analysis has shown that FeAl phase is the matrix of the examined alloy (Fig. 3). Diffractogram of the alloy with 58 at.\% aluminum indicates occurrence of not only $\mathrm{FeAl}$ matrix, but also $\mathrm{FeAl}_{2}$ phase, equal to 75.4 mass\% (24.6 mass\%), respectively, complying with the assumptions and with phase equilibrium diagram for $\mathrm{Fe}-\mathrm{Al}$ system. Microstructure of the examined material is characterized by presence of binary eutectics $\alpha_{2}(b)+\mathrm{FeAl}_{2}$ (Figs. 4, 5).

At present, alloy of $\mathrm{Fe}-\mathrm{Al}$ system are being studied, in order to determine other thermal properties, such as for example thermal conductivity, and electrical and mechanical properties. 


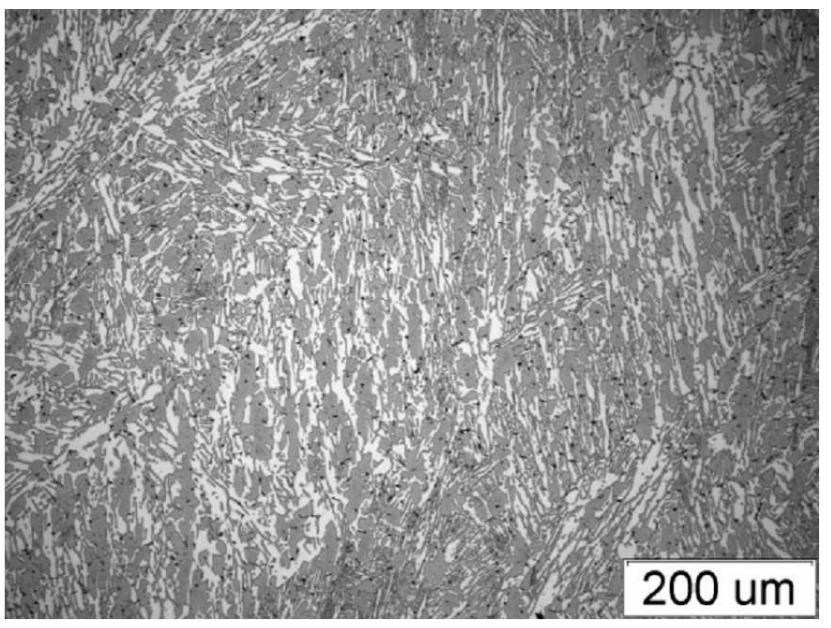

Fig. 4. Microstructure of 58Al.
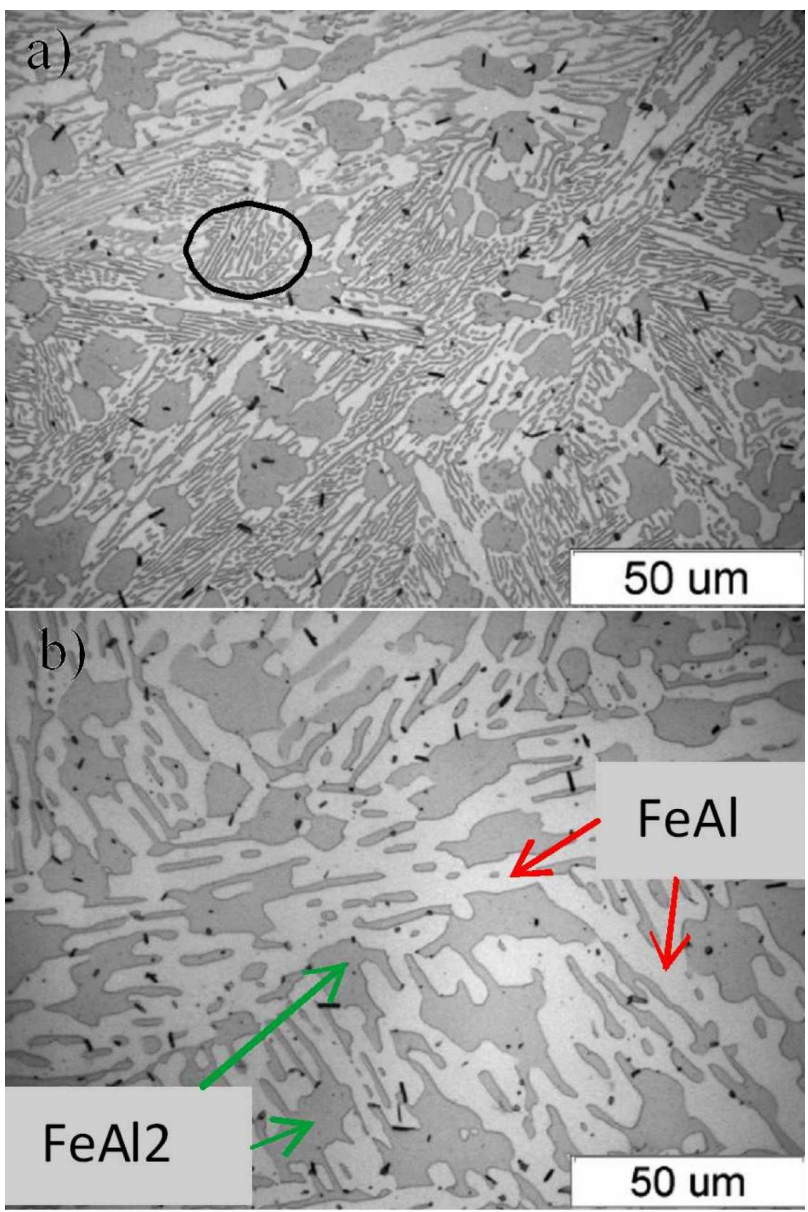

Fig. 5. Microstructure of $58 \mathrm{Al}$ (a), eutectics $\alpha_{2}(b)+$ $\mathrm{FeAl}_{2}$ (b).

\section{Summary}

The dilatometric studies carried out allowed for identification of phase transitions occurring during heating and cooling of the alloys, as well as determination of the value of average coefficient of linear thermal expansions in a broad range of the study temperatures. The matrix of the studied $58 \mathrm{Al}$ alloy is composed of an FeAl phase, and it is in a good accordance with the assumptions and with the phase equilibrium system. The investigated material containing 58 at.\% $\mathrm{Al}$ is characterized by a lower, while compared to the alloys with lower aluminum contents, average linear thermal expansion coefficient, equal to $15.90 \times 10^{-6} /{ }^{\circ} \mathrm{C}$ (in the case of iron, it is equal to $\left.12 \times 10^{-6} /{ }^{\circ} \mathrm{C}\right)[6]$. The recorded thermal effects on the dilatometric curve are inconsistent with the anticipated transformations in the $\mathrm{Fe}-\mathrm{Al}$ phase equilibrium system. At a temperature of about 840,770 , and $680^{\circ} \mathrm{C}$ on the dilatometric curve there appear minor faults - sudden changes in linear thermal expansion coefficient $\alpha$.

\section{Acknowledgments}

Financial support of Structural Funds in the Operational Programme - Innovative Economy (IE OP) financed from the European Regional Development Fund - Project No. POIG.01.01.02-00-015/09 is gratefully acknowledged.

\section{References}

[1] M. Salazar, A. Albiter, G. Rosas, R. Pérez, Mater. Sci. Eng. A 351, 154 (2003).

[2] J. Kansy, A. Hanc, M. Jabłońska, E. BernstockKopaczyńska, D. Giebel, Progr. Positron Annihil. 666, 50 (2011).

[3] B.V. Reddy, S.C. Deevi, Intermetallics 8, 1369 (2000).

[4] M. Jabłońska, A. Jasik, A. Hanc, Archiv. Met. Mater. 29, 16 (2008).

[5] M. Boufenghour, A. Hayoune, D. Hamana, J. Mater. Sci. 39, 1207 (2004).

[6] A. Śmiglewicz, M. Jabłońska, Def. Diff. Forum 326328, 587 (2012).

[7] O. Kubaschewski, IRON-Binary Phase Diagrams, Springer-Verlag, Berlin 1982, p. 5.

[8] L. Pająk, J. Kansy, A. Hanc, G. Dercz, M. Jabłońska, Archiv. Mater. Sci. Eng. 302, 81 (2008).

[9] PN-68/H-04500, Dilatometric tests of metals and their alloys.

[10] M. Jabłońska, A. Hanc, A. Szostak, Solid State Phenom. 163, 299 (2010). 